Title:

\title{
INJURIES IN SPORT
}

Author:

\author{
David S. Muckle
}

Publisher: John Wright \& Sons Ltd., Bristol

Price:

I find this a very difficult book to review. Sub-titled 'A Guide for the Accident Department and General Practice'. Mr. Muckle in his preface quotes that the book is 'addressed to the Casualty Department, the Orthopaedic Surgeon, the Rheumatologist, the General Practitioner and anyone else who is interested in sport'. For a book of 131 pages this would seem to me too broad a spectrum. Even allowing for the specific exclusion of Physiotherapy and Rehabilitation for the reasons given in Mr. Muckle's preface, the subject matter is still too wide for a satisfactory treatment in depth. Inevitably, therefore, certain ares will be relatively weak, and in this context I found the relative dismissal of Chondromalacia patellae in a mere 19 lines particularly disappointing. Surely there could have been space in the text for some mention of the lateral retinacular release as a valid surgical procedure in this condition, particularly if space could be found for the description of three separate operations for correction of that relative rarity, displacement of the peroneal tendons?

As another example of this contrast between the superficial and the detailed may be noted the generous allocation of space to description of surgical procedures around the shoulder joint while there is little more than a page devoted to the multiplicity of painful conditions around the foot.

The book is nicely produced with admirable illustrations and a clear text. It does, however, illustrate clearly the impossibility of producing on a small scale a text that will at once satisfy a wide range of different needs. One could argue that as 'a guide to the Accident Department and General Practice' virtually all the operative detail was superfluous while the exclusion of physiotherapy and rehabilitation from a book addressed to the Rheumatologist could also be criticised.

There is much in this book to recommend it to the afficionado but as a simple, brief, straightforward guide to the injuries of Sport it is not entirely satisfactory, particularly at a price of $£ 6.50$ !

J. G. P. Williams

\section{BOOK REVIEW}

Title: $\quad$ SPORTS INJURIES

Author: Russell Gibbs

Publisher: Sun Books, Melbourne, Australia

Price: $\quad$ (In Australia \$2.95. In U.K. on application)

This is a handy little book on injuries in sport with particular reference to first-aid which in his introduction Dr. Gibbs describes as 'written in the hope that it will provide information on and stimulate interest in the care of sporting injuries for a wider range of people than has been done before'.

It presents in a nut-shell some basic concepts of injury in sport, with particular reference to prevention, and the basic objectives of the organisation of care following injury. The specific procedures which form the second part of the book are set out simply and with useful mnemonics and illustrations. While in no sense comprehensive this section of the book does cover the major problems and their primary treatment.

In the third part on detailed procedures, Dr. Gibbs restricts himself to discussion of suitable remedial exercises and simple strapping and also provides a helpful suggestion of suitable first-aid equipment for general sports purposes.

Clearly one must regard this manual as a simple, practical guide for the coach or trainer and as the gentlest of nursery slopes for the medical practitioner. As such it admirably fulfils its ends and can be well recommended.

J. G. P. Williams 